\title{
Design, fabrication and testing of hydro turbine with composite path runner for ultra-low head application
}

Raj Kumar Chaulagain*1, Dhiraj Pokhrel², Kaurab Gautam², Nabin Khanal2, Harish Bhatt ${ }^{2}$

\begin{abstract}
This paper is focused on design a turbine with composite path runner for ultra low head application and finally analyze its performance under different test conditions. Literature review was the starting point of research and detailed design parameters for the turbine dimensions and materials were selected taking feasibility of fabrication and testing in hand. The testing was proposed on real site of Bagmati river at Kupandole, Lalitpur, Nepal where the turbine was subjected to fuse reeflowing water from the head of $1.3 \mathrm{~m}$ and flowrate of 78 LPS that taken as site parameter. The 3D model for the turbine was developed in CATIA. For turbine height of $0.77 \mathrm{~m}$ and runner minor diameter of $0.152 \mathrm{~m}$, simulations were carried out to find the most feasible number of blades, blade width, blade spacing, number of guide vanes and guide vane spacing using ANSYS simulation. Among the simulation the best arrangement was blade radial width of $62 \mathrm{~mm}$, blade spacing of $54 \mathrm{~mm}$, guide vane spacing of $36.5 \mathrm{~mm}$, total number of blades 25 and total number of guide vanes 7 keeping output power in mind. The experimental results were then compared with the data obtained from calculations and simulations. Turbine at part load of Qo/Qmax $=0.67$ was tested and the resulting maximum efficiency was $21.1 \%$ at 87 RPM with available flow rate of 52 LPS.
\end{abstract}

Keywords: ANSYS, CATIA, Composite path, Ultra low head, part load, LPS

\section{INTRODUCTION}

Rural electrification is often conjoined with optimal use of locally available resources like ultra low head resources in mountainous country Nepal, transmission of remotely generated power to unevenly distributed villages seems costlier [1]. Conceding with this fact, low and ultra low head are being used to satiate current power demand. Ultra-low head is the situations where the hydraulic head is less than $3 \mathrm{~m}$ or the water flow is more than $0.5 \mathrm{~m} / \mathrm{s}$ with zero head [2]. Locally established water mills and hydropower plants using Archimedeans Screw Turbine and Gravitational vortex plant are the good example of them. They are basically suitable for plain region of the country [3]. Composite path runner turbine works prominently on impulse principle.

1 Head, Department of Automobile and Mechanical Engineering, Thapathali Campus, Institute of Engineering, Tribhuvan University, Thapathali, Kathmandu, Nepal

2 Research Assistant, Department of Automobile and Mechanical Engineering, Thapathali Campus, Institute of Engineering, Tribhuvan University, Thapathali, Kathmandu, Nepal, kaurab97@gmail.com Corresponding author:

E-mail :rajkrc12@tcioe.edu.np,rajkrc12@gmail.com 


\section{Problem statement}

It is self evident that rural electrification can be achieved effectively by using locally available resources to the country like Nepal where demographical distribution is largely uneven. Especially in Terai region of country, there seems no valuable technological study to tap the energy from water resources flowing near-by them. So, this research aims to develop a low scale hydro turbine that might be a mile stone for developmental step.

\section{Research objective}

i. $\quad$ To design and simulate turbine with composite path runner for head of $1.3 \mathrm{~m}$ and 78 LPS.

ii. To fabricate complete turbine system as per design.

iii. To test the performance of turbine at real site condition.

\section{Literature review}

Turbine uses symmetrically curved vanes that are mounted to pair of continuous power transmission belts each of which revolves on a pair of grooved pulleys. The blades move in substantially linear paths on both the upstream and downstream sides where water strikes, which extend between the circumference of top and bottom pulley. In first series of blade, impulsive force is created that makes the blade move downward while at second series of blade, reactive force is generated which makes the blade move upward, resulting the runner to rotate generating mechanical power. Power generation from the turbine is based on Euler's turbine equation [4].

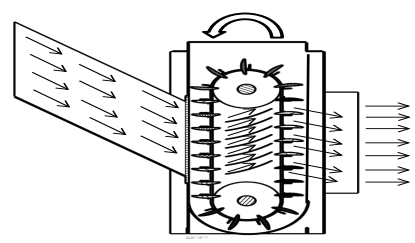

Fig: Schematic diagram demonstrating turbine working principle

Natel energy Inc of United states patented first turbine based upon composite path runner [5]. They used runner with symmetrically curved vanes mounted on a timing belt which would revolve on a pair of axles.

- $\quad$ Eberhard of Switzerland also developed turbine based upon the same principle that the blades that contribute to power output travel in the same direction as the fluid flow $50 \%$.

Nance of US also developed similar two stage turbines. In his invention the blades in the second stage are situated to receive direct input of fluid as well as fluid directed from the front blades after glancing off of them but his design suffered with confluent flow condition with two streams of flow.

Schneider with the objective to provide an improved system, method, and apparatus for a linear hydraulic impulse machine developed a linear hydraulic machine which utilizes reaction foils, operating with the principle of lift [6]. 


\section{Research Methodology}
a. Problem identification
b. Literature review
c. Field identification for design parameter
d. Design and simulation of turbine
e. Fabrication of system
f. Testing of the system
g. Result analysis
h. Final conclusion and recommendation

\section{Design Summary \\ Blade design}

- Blade was designed with the basic relation of inlet and blade angle from cross flow turbine which is, $\tan (\boldsymbol{\beta})=2 * \tan (\alpha)[8]$.

- $\quad$ Suitable angle of water velocity was chosen by performing ANSYS simulation.

\subsection{Runner design}

\begin{tabular}{|c|c|}
\hline Head & $1.3 \mathrm{~m}$ \\
\hline Flow rate (maximum possible to divert) & $78 \mathrm{LPS}$ \\
\hline Velocity & $3.25 \mathrm{~m} / \mathrm{s}$ \\
\hline Density of water & $1000 \mathrm{~kg} / \mathrm{m}^{3}$ \\
\hline
\end{tabular}

\section{Water inlet angle selected}

- $\quad$ Pitch circular diameter (PCD) calculated and inner and outer diameter of blade determined. $=$ and $\mathrm{Di} / \mathrm{Do}=0.66$ [7]

- $\quad$ Blade radial width is selected through difference of inner to outer diameter.

- Blade spacing determined through simulation

- Distance between shaft centers determined

\subsection{Formulae for shaft design}

\begin{tabular}{|l|c|}
\hline $\begin{array}{l}\text { Marin equation for endurance } \\
\text { limit of shaft }\end{array}$ & $=\left(\mathrm{K}_{\mathrm{a}} * \mathrm{~K}_{\mathrm{b}} * \mathrm{~K}_{\mathrm{c}} * \mathrm{~K}_{\mathrm{d}} * \mathrm{~K}_{\mathrm{e}} * \mathrm{~K}_{\mathrm{f}} * \mathrm{~S}_{\mathrm{e}}{ }^{\prime}\right)$ \\
\hline $\begin{array}{l}\text { Catalogue load rating }\left(\mathrm{C}_{10}\right) \mathrm{for} \\
\text { bearing }\end{array}$ & $\mathrm{C}_{10}=\mathrm{F}_{\mathrm{D}}\left[\frac{\mathrm{x}_{\mathrm{D}}}{\mathrm{x}_{\mathrm{D}}+\left(\theta-\mathrm{x}_{0}\right)\left(1-\mathrm{R}_{\mathrm{D}}\right)^{1 / \mathrm{b}}}\right]^{1 / \mathrm{b}}$ \\
\hline Head loss due to friction & $\Delta h_{f}=\mathrm{f} \frac{L V^{2}}{2 g D_{e}}$ \\
\hline Reynolds's no & $\frac{\rho D_{e V_{a v g}}}{\mu}$ \\
\hline diametric ratio & $\frac{D i}{D_{t}}=0.66$ \\
\hline Impulsive Force on blade & $\mathrm{F} 1=\rho * \mathrm{Q}^{*}\left(\mathrm{~V}_{\mathrm{w} 1}-\mathrm{V}_{\mathrm{w} 2}\right)$ \\
\hline
\end{tabular}

$[9,10,11,12]$ 
Taking factor of safety (n) as 13.55, the diameter of shaft is found to be $25 \mathrm{~mm}$. The diameter of safety is taken in such a way that is will be easy for manufacturing taking account of safety requirements.

\subsection{Calculation result}

\begin{tabular}{|l|l|}
\hline Inlet dimension & $200 \mathrm{~mm} * 300 \mathrm{~mm}$ \\
\hline Velocity of water at inlet & $3.25 \mathrm{~m} / \mathrm{s}$ \\
\hline Force on first series of blade & $226.2 \mathrm{~N}$ \\
\hline Force on second series of blade & $55.38 \mathrm{~N}$ \\
\hline Ultimate tensile strength of blade material $(1020 \mathrm{CD})$ & $470 \mathrm{MPa}$ \\
\hline Actual flow rate & $52 \mathrm{LPS}$ \\
\hline
\end{tabular}

\section{CFD analysis of model}

$$
\begin{aligned}
\mathrm{d}=\left[\frac { 1 6 \mathrm { n } } { \pi } \left\{\frac{1}{\mathrm{~S}_{\mathrm{e}}}\right.\right. & {\left[4\left(\mathrm{~K}_{\mathrm{f}} * \mathrm{M}_{\mathrm{a}}\right)^{2}+3\left(\mathrm{~K}_{\mathrm{fs}} * \tau_{\mathrm{a}}\right)^{2}\right]^{1 / 2} } \\
& \left.+\frac{1}{\mathrm{~S}_{\mathrm{yt}}}\left[4\left(\mathrm{~K}_{\mathrm{f}} * \mathrm{M}_{\mathrm{m}}\right)^{2}+3\left(\mathrm{~K}_{\mathrm{fs}} * \tau_{\mathrm{m}}\right)^{2}\right]^{1 / 2}\right]^{1 / 3}
\end{aligned}
$$

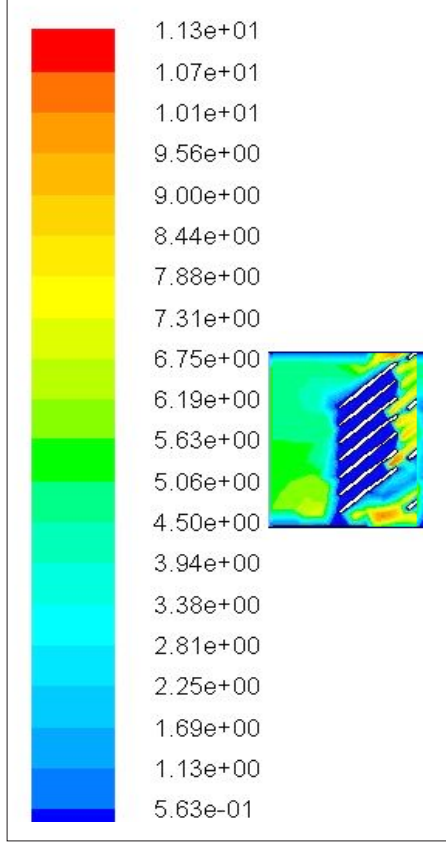

Fig: Velocity contour for

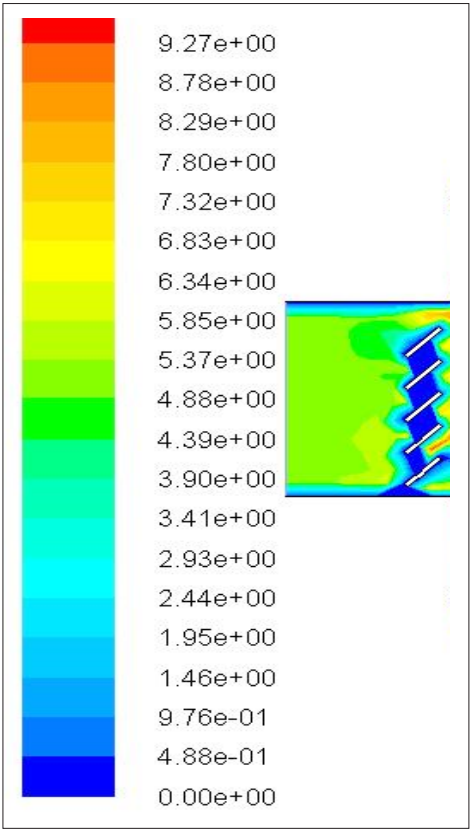

Fig: Velocity contour for $30 \mathrm{~mm}$ blade spacing 


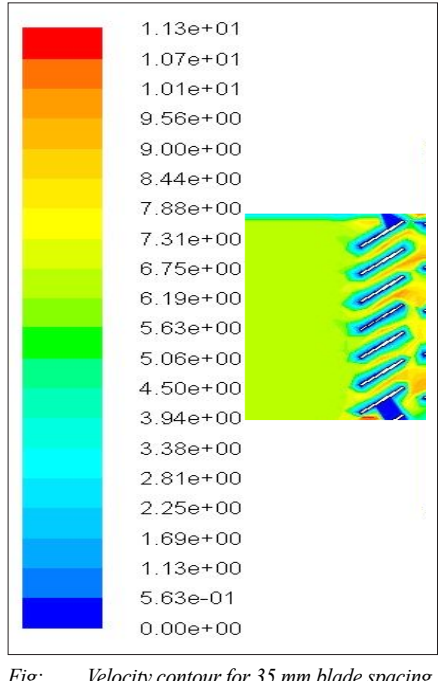

Fig: $\quad$ Velocity contour for $35 \mathrm{~mm}$ blade spacing

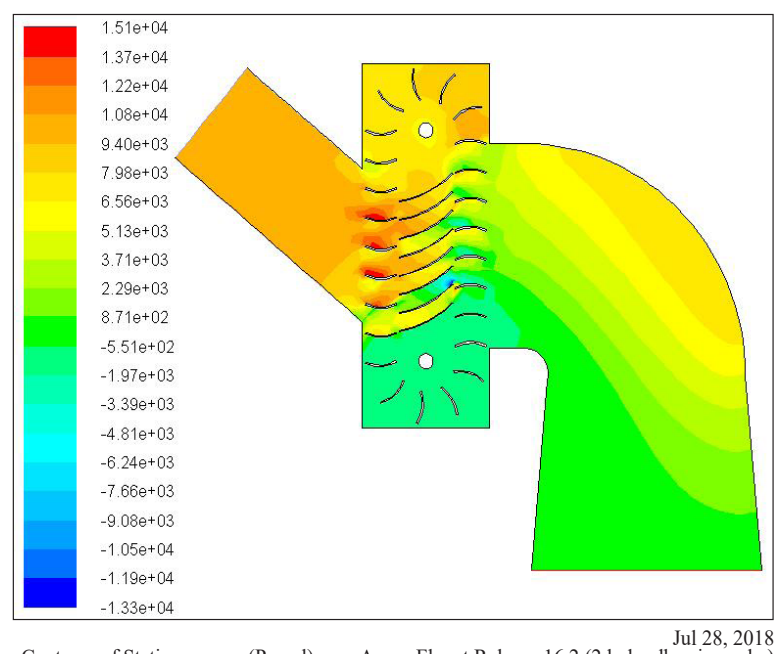

Contours of Static pressure (Pascal) Ansys Fluent Release 16.2 (2d, dp, dbns imp. ske) Fig: Pressure contour in turbine $(\mathrm{Pa})$

CFD simulation showed that the system has more efficiency when draft tube is used. To validate that with experiment, the testswere aimed to conduct at Bagmati River near Kupandole Bridge.

\section{Fabrication}

Penstock, casing, runner and brake dynamometer were fabricated and assembled. Mild steel was used primarily to fabricate them. Different standard machine toolswere used for fabrication of the complete system.

\section{Testing and Data Analysis}

\subsection{Site description:}

Testing of turbine was done at real site on Bagmati River atKupondole, Lalitpur, Nepal. Suitable arrangement for the placement of turbine and other accessories on the safe side of river was madefor ease of testing. The testing instruments and test sheet were made prepared for data measurement.

\subsection{Measurement and data analysis}

During preparation of test, flow arrangement was only possible up-to 52 LPS. So, it was tested in part load operating conditions.Brake dynamometer was used to measure the mechanical load and optical type tachometer was used to measure the rotational speed of the turbine. Various input and output parameters were measured and recorded on test sheet. Different test results obtained were plotted to develop various performance curve which are as following. 


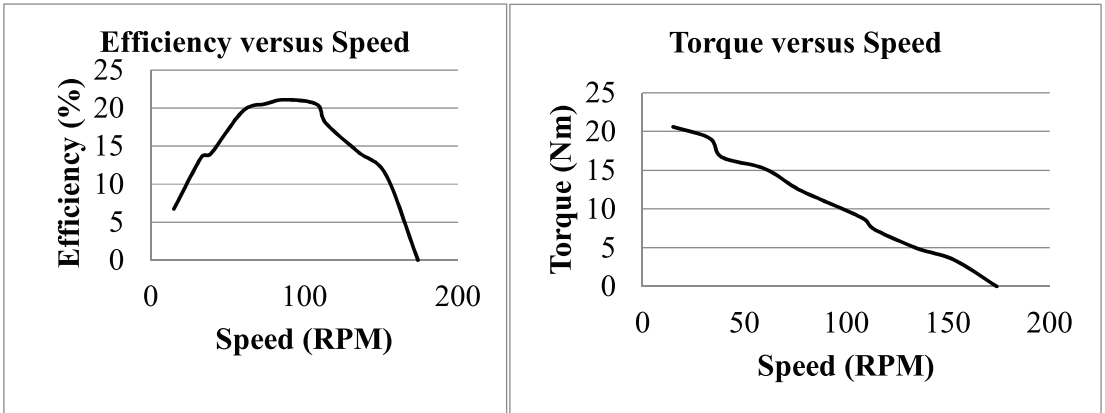

Fig: Variation of efficiency with speed

Fig: Variation of torque with speed

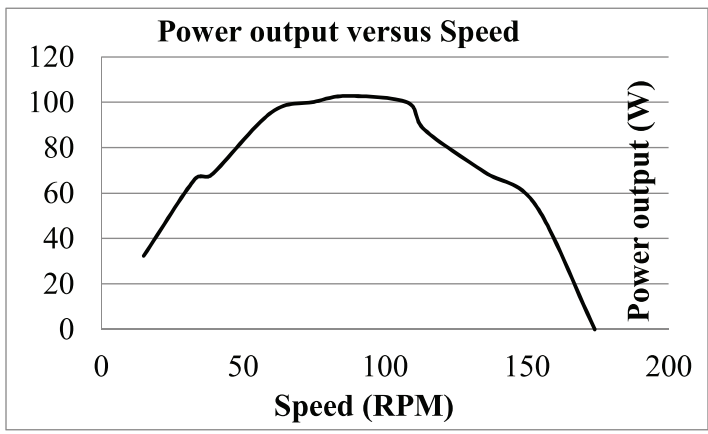

Fig: Variation of power output with speed

The maximum overall efficiency of the turbine was found to be $21.1 \%$ at $87 \mathrm{RPM}$ at the part load of $0.67 \mathrm{Q}_{\max }$. If the required amount of flow could have been directed to turbine then the output of the turbine could have increased and so as the efficiency. From this result it was concluded that efficiency and power output graph found to be varied with speed, non-linearly. Linear relationship in between torque and speed denotes turbine can be operated on any speed without lose on torque. That makes it possible to operate turbine at speed satisfying maximum efficiency condition.

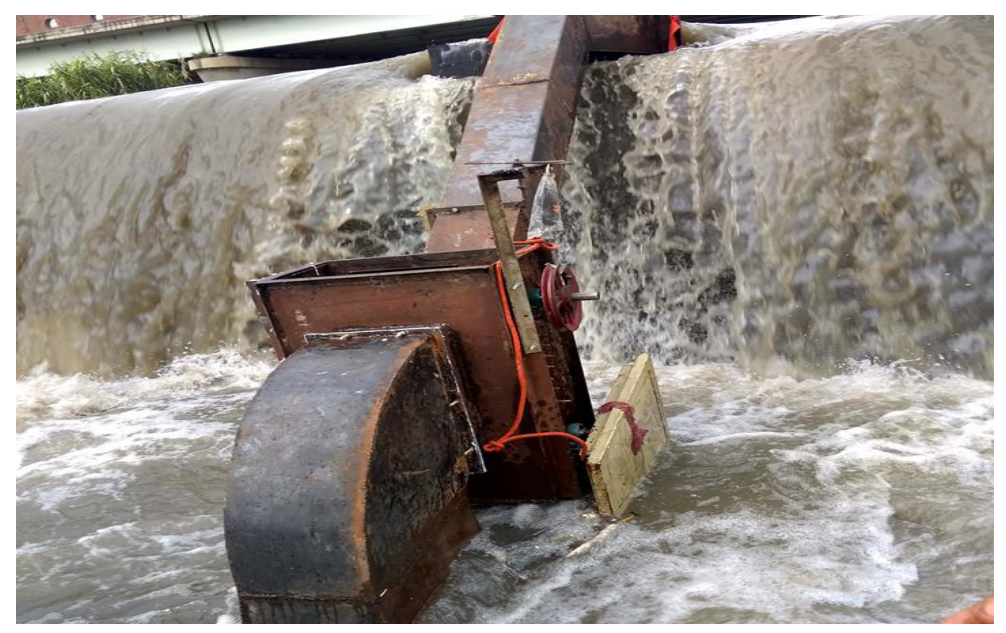

Fig: Testing of turbine 


\section{Conclusion}

The system works better with draft tube rather than without draft tube.

The composite path runner really works with higher torque rather than the speed and generates mechanical power further that can be converted to electrical using speed increasing devices and generators.

Performance of turbine was tested for ultra-low head application with maximum efficiency of $21.1 \%$ at 87 RPM.

\section{Recommendations}

a. Three-dimensional simulation of design can result more efficient blade profile.

b. Manufacturing and selection of material properties can lead to better output.

c. Testing on suitable test rig can result more accurate performance.

\section{Acknowledgement}

To carry out the research activities, entire concerned organizations are highly acknowledged for their great support.

- Nepal Academy of Science and Technology, Khumaltar, Lalitpur, Nepal.

- $\quad$ Center for Energy Studies, IOE, TU, Lalitpur, Nepal.

- $\quad$ Thapathali Campus, IOE, TU, Kathmandu, Nepal.

- $\quad$ Vortex Engineering Concern Pvt. Ltd, Kathmandu, Nepal. ${ }^{3}$

[1] (n.d.). Retrieved August 01, 2018, from WEPA : from http://www.wepa-db.net/policies/state/ nepal/state.htm

[2] Koirala, N. \&. (2017). Review of low head turbine systems of Nepal for rural elecrrification. ICERA, 861-869.

[3] Ultra-low-head hydroelectric technology: A review. (2017, August). Retrieved July 27, 2018, from Researchgate https://www.researchgate.net/publication/316657511_Ultra-low-head_ hydroelectric_technology_A_review

[4] M.S.Güney, K. (December,2010). Hydrokinetic energy conversion systems: A technology status review. Science Direct, 2996 - 3004.

[5] Natel Energy.(April 04). Retrieved Fabruary 04,2018,from https://www.natelenergy.com

[6] Global specialist and energy management.(n.d). Retrieved May 04,2018, from https://www. schnider-electric.com.

[7] BRESLIN, W. R. SMALL MICHELL (BANKI) TURBINE: A Construction Manual . 3706 Rhode Island Avenue, Meryland USA: VOLUNTEERS IN TECHNICAL ASSISTANCE

[8] M. Sinagra, V. S. (2014). Cross-flow Turbine Design for Variable Operating Conditions. Science Direct, $1539-1548$.

[9] (n.d.). Retrieved july 28, 2018, from MIT: http://web.mit.edu/16.unified/www/FALL/thermodynamics/ notes/node91.html

[10] Biswokarma, M. B. (2012). Computation of Head Losses in Hydropower Tunnels Researchagte.

[11] Rajput, R. (2008). A textbook of Hydaraulic Machine. New Delhi: S. Chand and Copmpany.

[12] Richard G. Budynas, J. K. (2016). Shigley's Mechanical Engineering Design . Chennai: McGraw Hill Publication (India) Pvt Ltd. 